\title{
Em favor de uma definição normativa de laicidade: uma resposta a Marcelo Camurça
}

\author{
In favor of a normative definition of Secularism: \\ a response to Marcelo Camurça
}

Mailson Fernandes Cabral de Souza*

\begin{abstract}
Resumo
Este texto é uma resposta ao artigo $A$ questão da laicidade no Brasil: mosaico de configurações $e$ arena de controvérsias, publicado no dossiê Religião, Direitos Humanos e Direitos da Natureza de Horizonte, em 2017. Abordarei alguns pontos que estruturam a composição do artigo e que considero problemáticos, uma vez que fazem um recorte arbitrário da discussão teórica sobre o conceito de laicidade. Para o autor, inexiste uma definição normativa pré-existente do que seja a laicidade. Com base em uma breve revisão bibliográfica sobre o tema e analisando a ordem de sustentação dos argumentos levantados pelo autor, mostrarei que a noção de laicidade normativa não é somente possível, como também existente e que não levar isso em consideração implica na negação de outras perspectivas de trabalho sobre a temática. Nesse sentido, defendo que tal lacuna compromete a noção de mosaico religioso que é proposta no artigo.
\end{abstract}

Palavras-chave: Laicidade; Liberdade Religiosa; Marcelo Camurça.

\begin{abstract}
This text is a response to the paper The issue of secularism in Brazil: mosaic of configurations and the sand of controversy, published in the dossier on Religion, Human Rights and the Rights of Nature in Horizonte in 2017. I will address some points that structure the composition of the article and which I consider problematic, since they make an arbitrary clipping of the theoretical discussion about the concept of secularity. For the author, there is no pre-existing normative definition of what secularity is. Based on a brief bibliographical review on the subject and analyzing the order of support of the arguments raised by the author, I will show that the notion of normative secularism is not only possible but also existing and that not taking this into account implies the negation of other perspectives work on the subject. In this sense, I argue that such a gap compromises the notion of religious mosaic that is proposed in the paper.
\end{abstract}

Keywords: Secularism; Religious Freedom; Marcelo Camurça.

Comunicação submetida em 29 de janeiro de 2018 e aprovada em 25 de agosto de 2018

* Mestre em Ciências da Religião pela Universidade Católica de Pernambuco. Membro do Observatório Transdisciplinar das Religiões no Recife. País de origem: Brasil. E-mail: mailsoncabral@yahoo.com.br. 


\section{Introdução}

A laicidade é um tema a respeito do qual tive que estudar durante a escrita da minha dissertação de mestrado, em 2016. No período, dediquei-me a ler o que pude sobre o assunto, visto que o foco de minha pesquisa, as políticas públicas para a promoção da liberdade e da diversidade religiosa, tocava diretamente nessa questão.

Foi assim que passei a me interessar pelo tema da laicidade e tive ocasião de aprofundar os estudos sobre ela após o término do mestrado. Esse percurso levoume ao artigo A questão da laicidade no Brasil: mosaico de configurações e arena de controvérsias, escrito por Marcelo Camurça e publicado em Horizonte, em 2017.

$\mathrm{O}$ artigo parte da recusa de um enquadramento teleológico-normativo na apresentação das relações entre as religiões e o Estado no Brasil. A justificativa do autor para essa postura é a de evitar um modelo universal que lhe sirva de paradigma, uma vez que isso apagaria as diferenciações entre os movimentos religiosos nessas relações. Tal apagamento não levaria em consideração as disputas, negociações, acordos e desacordos que dão a dinâmica dos atores sociais e estatais que estão envolvidos nessa conjuntura.

Para evitar semelhante postura, ele opta também por não enquadrar normativamente a laicidade. Melhor dizendo, afirma que "não existe definição normativa pré-existente do que seja laicidade" (CAMURÇA, 2017, p. 855). Em função do teor polissêmico que a noção adquiriu no Brasil, ela é regida pelos segmentos que a invocam na disputa pelo espaço público. A fim de demonstrar isso, Camurça (2017) desenvolve no artigo a noção de mosaico religioso para mostrar, a partir de diferentes trabalhos que evidenciam o quão multifacetado é o cenário religioso e a disputa pelo espaço público, a pluralidade da laicidade. 
No entanto, em sua proposta de escapar do paradigma do modelo universal, o autor incorre em uma falha análoga à que critica: apagar os pontos de vista divergentes do seu. Ao afirmar que não preexiste uma definição normativa de laicidade, ele ignora trabalhos como os de Kintzler (2008) e Lacerda (2014), que defendem a existência normativa da laicidade e a sua importância na compressão do papel da religião no espaço público. Somado a isso, Camurça (2017) incorre em outros dois problemas: o de aplicar de forma indiscriminada o conceito de laicidade ao Estado e à sociedade, e o de se valer de autores que lhe fornecem subsídios frágeis para a sustentação da noção de mosaico religioso, comprometendo a proposta do artigo.

Dito isso, irei me deter, daqui por diante, a comentar os seguintes pontos do texto na ordem em que aparecem em seu resumo e que subdividirei na próxima seção: a) A recusa de um enquadramento teleológico e normativo da laicidade; b) O mosaico de configurações diferenciadas que expressam situações de laicidade desiguais; c) A laicidade entendida como um processo que envolve conflitos, negociações e acordos em marchas e contramarchas; d) A ausência de uma definição normativa pré-existente de laicidade, sendo ela tão somente invocada em função de interesses próprios dos segmentos que disputam o poder de definir o papel da religião no espaço público. Esses, basicamente, são os pontos centrais que sustentam o texto, em relação aos quais gostaria de expressar as minhas divergências.

\section{Problemas conceituais em foco}

a) O autor, já na introdução do artigo, começa situando a posição que sustentará ao logo do texto, isto é, a de recusa ao enquadramento teleológiconormativo da laicidade:

A partir da crítica à concepção teleológica e eurocêntrica da noção de secularização, e, por consequência, da de laicidade enquanto um modelo único, empreendida por José Casanova (1994) e Talal Asad (2003), em obras hoje já tornadas referências, abriu-se a perspectiva para enfoques 
mais plurais destes conceitos. Estes passaram a levar em conta contextos nacionais e civilizacionais, ritmos, trajetórias singulares pelos quais a relação entre religião, modernidade e esfera pública vem se estabelecendo (CAMURÇA, 2017, p. 856).

A justificativa apresentada por Camurça (2017) para essa demarcação, tendo por base os diferentes acordos estabelecidos entre as religiões e os Estados modernos nos mais diversos lugares do mundo, é a de "pensar estilos distintos de laicidade(s), caminhos próprios de construção deste(s) regime(s)" (CAMURÇA, 2017, p. 856). A abordagem permitiria, portanto, demonstrar que as formas sob as quais os Estados se relacionam com as religiões são múltiplas, resultando em regimes de laicidade distintos.

A meu ver, a justificativa teórica adotada não foi boa. Tomar a crítica de Casanova (1994) e Asad (2003) sobre a secularização/laicidade não o exime de mostrar o que há de problemático nessas concepções por eles criticadas. Ao simplesmente dizer que a concepção clássica de secularização é teleológica e eurocêntrica e que, por tabela, a laicidade toma o mesmo rumo - e que, na contemporaneidade, há enfoques mais plurais sobre esses conceitos -, o autor dá um tratamento muito superficial à questão (apenas um parágrafo) e logo se lança à perspectiva comparativa da laicidade.

Particularmente, não acho que os autores escolhidos na abertura do artigo sejam muito pertinentes para o quê o artigo se propõe, pois tanto a crítica de Asad (2003) como a de Casanova (1994) se concentram sobre a secularização e não sobre a laicidade, não havendo, em certos momentos, uma distinção precisa entre as duas coisas. Nos trabalhos de Casanova $(2006 ; 2011)$ que li durante o mestrado e que pude trabalhar em artigo (SOUZA, 2017), isso pareceu-me evidente; já no caso de Asad (2003), o meu conhecimento é de terceira mão. Em razão disso, penso que o enquadramento normativo da laicidade não seja um problema, pelo contrário, ele é mais útil no entendimento das relações entre religião e Estado do que a sua recusa. Autores como Huaco (2008), Kintzler (2008) e Lacerda (2014) oferecem reflexões muito pertinentes para isso. Obviamente, é preciso deixar claro o que estou 
entendendo por normativo. Parto da perspectiva da Teoria Política Normativa, na qual o normativo se ocupa com aquilo que "deve ser", com valores e crenças, e com escolhas individuais e coletivas. Isto, por sua vez, não implica necessariamente que tal teoria não tenha base empírica. Pelo contrário, muitas de suas formulações têm diagnósticos bem elaborados e convincentes daquilo que “é”, isto é, do mundo atual, e esses resultados são muito importantes na reflexão daquilo que "deve ser" (FERES JÚNIOR, 2010).

Nesse sentido, a laicidade pode ser compreendida a partir da formalização de tipos e de padrões de sua institucionalização. Tomando esse viés, Gustavo Lacerda (2014) oferece uma definição simples e interessante de laicidade:

o Estado não professa nem favorece (nem pode professar ou favorecer) nenhuma religião; dessa forma, ele contrapõe-se ao Estado confessional em que se inclui o assim chamado "Estado ateu", considerando que este assume uma posição caracteristicamente religiosa, mesmo que seja em um sentido negativo. Dessa forma, seguindo a laicidade, o Estado não possui doutrina oficial, tendo como consequências adicionais que os cidadãos não precisam filiar-se a igrejas ou associações para terem o status de cidadãos e inexiste o crime de heresia (ou seja, de doutrinas e/ou interpretações discordantes e/ou contrárias à doutrina e à interpretação oficial). (LACERDA, 2014, p. 181).

Nesse contexto, a filiação religiosa não se constitui como prerrogativa para o direito à cidadania, e o poder público fica imobilizado pela abstenção de assumir uma religião oficial ou dogma civil. Há, dessa forma, uma dissociação entre lei civil e normas religiosas: passa-se a organizar a vida política do Estado sem a prerrogativa de um fundamento transcendente (SOUZA, 2017). Em síntese, uma definição normativa da laicidade não implica necessariamente numa abordagem reducionista da questão. Pelo contrário, ela permite entender como se inscreveu e regulou, desde a modernidade, a relação entre Estado e as religiões no ocidente sob a forma das leis. A perspectiva comparativa levanta por Camurça (2017) não contempla esse aspecto, a meu ver, fundamental para a discussão a que ele se propõe. 
b) Outro problema, que se encadeia ao anterior, é que o autor aplica a noção de laicidade tanto ao Estado como à sociedade. Na visão de Camurça (2017), isso não se apresenta como um embaraço para a sua proposta:

gostaria de apresentar quatro cenários que, a meu ver, expressam espaços onde diversos atores sociais (laicos e religiosos) investem discursos, dispositivos legais, midiáticos, políticos para estabelecer uma configuração do que compreendem como o lugar do religioso no espaço público, ou do que seja um regime de laicidade (CAMURÇA, 2017, p. 860 [grifos meus]).

Ao estabelecer essa configuração para a sua análise, os termos lugar do religioso no espaço público e regime de laicidade aparecem como intercambiáveis para o uso do conceito de laicidade. Essa compreensão é problemática, posto que não há equivalência entre eles. O primeiro refere a laicidade à sociedade e o segundo ao Estado, no entanto, como preceito político, a laicidade se aplica somente ao segundo termo.

A laicidade é um conceito que deve ser aplicado ao Estado e não à sociedade. Para essa última, valeria a noção de secularização, como propõe o próprio Casanova (2006), uma vez que ela é um processo social mais amplo que corresponde à progressiva perda de influência dos valores religiosos no espaço público. É por isso que critiquei mais acima a escolha dos autores com que Camurça (2017) abre o artigo: o foco deles é a secularização e não a laicidade, o que não converge para a análise - e, nesse aspecto, tanto as análises de Mariano (2011) como as de Giumbelli (2013) seguem a mesma direção da que é feita por Casanova (2006; 2011). Nesse sentido, é mais pertinente a distinção feita por Huaco (2008, p. 47), na qual o autor mostra o que cada conceito elucida: "a laicidade é a expressão político-institucional do processo de secularização (das instituições estatais, de seu ordenamento, de suas políticas, etc.) que acaba moldando-se formalmente mediante normas, princípios e valores jurídicos”. A laicidade, assim, é um princípio que oscilará para a sua maior ou menor efetivação em cada contexto político, a depender do grau de secularização de uma determinada sociedade. 
Outro dado interessante apontado por Huaco (2008) é que nos países de hegemonia católica as discussões sobre a laicidade se tornaram mais intensas, enquanto que em países de predominância protestante há um maior foco para a noção de secularização. Talvez seja isso que impeça Casanova (2011) de trabalhar de forma mais aprofundada essa diferenciação. A laicidade, tomada como valor político, é própria da emergência do contexto republicano francês e dos países inspirados nesse modelo. Mariano (2011) também afirma que os processos de laicização em diversos países da América Latina foram inspirados nesse mesmo ideário. Assim, podemos dizer que a laicidade é uma situação institucional e, paralelamente, um valor político a ser respeitado, em tese, nessas sociedades.

Diante disso, penso que a noção de mosaico "de distintos cenários onde pontos de vista diversos se expressam" (CAMURÇA, 2017, p. 860), desenvolvida no artigo, é problemática, visto que coloca a laicidade no lugar da secularização e estabelece uma crítica a partir dessa compreensão, isto é, deslocando o foco do conceito para os atores sociais:

Esta breve menção a situações de comparação já aponta para uma dimensão mais plural e nuançada da laicidade do que uma pretensa condição de plena autonomia e preeminência do Estado em relação às religiões como modelo ideal a ser seguido, sob pena de uma maior e mais ativa presença religiosa na esfera pública ser classificada como uma descaracterização do modelo. Este modelo, então, tende a reduzir a análise da laicidade a um esquema bipolar, como se sua dinâmica em um país ou região se resumisse, de um lado, em iniciativas de implementação de atos de soberania e neutralidade do Estado em relação às religiões existentes, $e$, de outro, de iniciativas de confessionalização da esfera pública por religiões, ultrapassando os limites da normatividade republicana do "bem comum" (CAMURÇA, 2017, p.858 [grifos meus]).

Diante do que foi exposto, a crítica do autor não se sustenta, pois levanta um espantalho. O que, no seu artigo, é chamado de laicidade ou laicidades - visão tomada a partir de Giumbelli (2013) - é o entendimento de que os atores sociais dão à relação entre religião e Estado, mais especificamente, à definição do papel da religião no espaço público. Compreender como isso funciona e se constitui se dá no campo discursivo desses grupos, assim como a circulação dos sentidos da laicidade, 
da secularização, da política, etc. Isso não se confunde como a noção de laicidade, sequer no seu nível mais pragmático.

c) Por causa disso, o conceito de laicidade, entendido como um processo que envolve conflitos, negociações e acordos em marchas e contramarchas, também me parece difícil de ser sustentado. Na verdade, esse terceiro ponto fundamenta o anterior, pois quando o autor passa a apresentar as diferentes laicidades, o que ele faz é tão somente uma grande revisão (review) dos trabalhos que versam sobre o tema do que propriamente um mosaico. Tal review é interessante dada à quantidade e qualidade das pesquisas que foram trazidas à baila, porém ela não consegue se transformar num mosaico. O autor expõe uma síntese de cada uma das pesquisas e, a partir disso, deduz uma comparação das laicidades, contudo essa comparação não aparece. A sensação é que o artigo é, sobretudo, informativo, e nisso ele vai bem, porém falha na parte propositiva, que seria o mosaico e a(s) laicidade(s) como processo - e que me parece ser seu objetivo maior. Aqui firmo uma crítica ao plural do termo laicidade, isto é, laicidades. E me refiro mais à proposta de Giumbelli (2013) do que a apresentada pelo autor. O problema de concebê-la nesses termos, além dos já mencionados, é que, se considerarmos essa pluralidade caso a caso, o trabalho com tipologias se torna inviável, visto que cada vez que o termo é empregado pelos atores sociais em um dado contexto ele pode adquirir uma nova significação. Seria bem mais simples falar sobre relações de Estado, religião e espaço público:

o termo "laicidade" no país parece funcionar mais como uma "referência" utilizada para tratar das relações entre religiões e Estado, referência esta sempre valorizada e adaptada aos interesses de cada um destes segmentos sociais, civil ou religioso (CAMURÇA, 2017, p. 882).

Aqui me parece que o autor se aproxima disso que falei, embora no parágrafo posterior retorne à ideia do Giumbelli (2013). Se o autor tivesse focado nos usos que os diferentes grupos dão ao termo em suas disputas e práticas discursivas, talvez fosse mais produtivo, uma vez que fecharia melhor com a ideia do mosaico e até lhe daria melhor fundamentação, evitando os embaraços causados 
pela má distinção entre secularização e laicidade. Ele se ocuparia em investigar a política dos sentidos gerada pela laicidade e como isso irrompe no espaço público, seja por meio dos fundamentalismos, das lutas por emancipação social ou até mesmo como isso se inscreve nas formas da lei.

d) Por fim, gostaria de tratar do último ponto que elenquei do texto. Camurça (2017) diz, com todas as letras no resumo do artigo, que não existe noção normativa preexistente de laicidade e que a noção é tão somente invocada em função de interesses próprios dos segmentos que disputam o poder de definir o papel da religião no espaço público:

como não existe nenhuma definição normativa preexistente do que seja laicidade, o que o texto postula é que, pelo caráter polissêmico que adquiriu no Brasil, esta noção é sempre invocada pelos segmentos em disputa - laicos e religiosos - de acordo com suas concepções e interesses próprios (CAMURÇA, 2017, p. 855 [grifos meus]).

Ora, como assim não existe definição normativa da laicidade? A recusa ou desconhecimento de um conceito não exclui a sua existência. $\mathrm{O}$ autor falhou nessa colocação ao ignorar a perspectiva normativa da laicidade - e foi justamente isso o que primeiro chamou a minha atenção no artigo. Valeria a pena ter dado um bom motivo para essa recusa ao invés de simplesmente eliminar de seu eixo argumentativo uma posição que lhe é contrária. A escolha de não trabalhar com a perspectiva normativa é uma opção teórica e deveria constar apenas como tal. Ao dizer que a laicidade, tomada numa perspectiva normativa, não existe ele está negando a existência de trabalhos como os de Huaco (2008), Kintzler (2008), Lacerda (2014) e Souza (2017), que a investigam justamente nessa perspectiva. As possibilidades de disputa de sentidos da laicidade pelos diferentes atores sociais só se tornam existentes porque elas deslizam do campo normativo para se tornarem objeto de disputa, ou seja, é porque elas preexistem normativamente que a concorrência acontece. Por isso, há uma clara contradição expressa no artigo e que depõe contra a própria possibilidade de criação de um mosaico, visto que apaga o lugar de origem da laicidade nesse debate. 


\section{Considerações finais}

A despeito das críticas levantadas, devo elogiar a revisão de literatura sobre o tema executada pelo autor. Ele sintetiza bem as principais pesquisas feitas no Brasil sobre o tema laicidade (inclusive algumas no exterior) e seus correlatos liberdade religiosa, intolerância, etc. O conteúdo das pesquisas está atualizado e exposto de forma clara, situando bem o leitor que adentra na discussão, além de ser mantida a unidade temática do texto do início ao fim. É importante ressaltar isso, dada à extensão do artigo e à complexidade do tema. Particularmente, gostaria muito que ele tivesse sido publicado no período em que redigia minha dissertação de mestrado, em 2016. Teria sido de enorme valia, visto que estudei algo muito próximo ao tema. Senti falta de ter sido mencionado no artigo algum estudo sobre o discurso político do Comitê Nacional de Respeito à Diversidade Religiosa, uma vez que a sua criação é um marco no campo das políticas públicas para a promoção da liberdade e da diversidade religiosa no Brasil, embora talvez o mesmo não possa ser dito quanto aos resultados de sua atuação.

Pelo que precede, espero que a minha resposta ao artigo seja digna de uma tréplica. Sei que não é bem nosso costume, no Brasil, confrontar o autor de um artigo pelas posições por ele assumidas, mas de simplesmente concordar (um acordo de compadres) ou discordar (de desafetos dos quais se evita até mencionar o nome), sem que isso estabeleça uma discussão que faça o conhecimento progredir. Por isso, interpelo Marcelo Camurça a fim de que ele marque sua posição acerca do que escreveu, uma vez que o modo como a laicidade foi exposta em seu estudo me parece muito problemática. 


\section{REFERÊNCIAS}

ASAD, Talal. Formations of the secular. Stanford: Stanford University Press, 2003.

CASANOVA, José. Public religions in a modern world. Chicago: University Chicago Press, 1994.

CASANOVA, José. Rethinking Secularization: a global comparative perspective. The Hedgehog Review, Charlottesville, v. 8, n. 1-2, p. 7-22, 2006.

CASANOVA, José. The Secular, Secularizations, Secularisms. In: CALHOUN, Craig; JUERGENSMEYER, Mark; VANANTWERPEN, Jonathan. (Org.). Rethinking Secularism. New York: Oxford University Press, 2011. p. 54-74.

CAMURÇA, Marcelo Ayres. A questão da laicidade no Brasil: mosaico de configurações e arena de controvérsias. Horizonte, Belo Horizonte, v. 15, n. 47, p. 855-886, jul./set. 2017. Disponível em:

<http://periodicos.pucminas.br/index.php/horizonte/article/view/P.21755841.2017v15n47p855/12283>. Acesso em: 20 out. 2017.

FERES JÚNIOR, João. Teoria política contemporânea: uma introdução. Rio de Janeiro: Elsiver, 2010.

GIUMBELLI, Emerson. Para estudar a laicidade, procure o religioso. In: BÉLIVEAU, Verónica Giménez; GIUMBELLI, Emerson (Org.). Religión, Cultura e política en las Sociedades del siglo XXI. Buenos Aires: Biblos, 2013. p. 43-68.

HUACO, Marco. A laicidade como princípio constitucional do Estado de Direito. In: LOREA, Roberto Arriada. (Org.). Em defesa das liberdades laicas. Porto Alegre: Livraria do Advogado, 2008. p.33-80.

KINTZLER, C. Qu'est-ce que la laïcité? Paris: Vrin, 2008.

LACERDA, Gustavo Biscaia de. Sobre as relações entre Igreja e Estado: conceituando a laicidade. In: CONSELHO NACIONAL DO MINISTÉRIO PÚBLICO. (Org.). Ministério Público - Em defesa do Estado Laico. Brasília: Conselho Nacional do Ministério Público, 2014. v.1 p. 179-206.

MARIANO, Ricardo. Laicidade à brasileira: católicos, pentecostais e laicos em disputa na esfera pública. Civitas, Porto Alegre, v. 11, n. 2, p.238-258, 2011.

SOUZA, Mailson Fernades Cabral de. Laicidade e liberdade religiosa no Brasil: situando a discussão entre religião e política. Interações - Cultura e Comunidade, Belo Horizonte, v. 12, p. 77-93, 2017. 